\title{
VITAMIN C INCREASES THE LEVEL OF LACTATE DEHYDROGENASE IN RATS 'ORAL SQUAMOUS CELL CARCINOMA
}

\section{Sahar EL Hadad}

Department of Biological Science: Faculty of Science: King Abdulaziz University: Jeddah: KSA Research center of Genetic Engineering and Bioinformatics, VACSERA, Cairo, Egypt

Received - January 05, 2018; Revision - April 02, 2018; Accepted - April 24, 2018

Available Online-April 25, 2018

DOI: http://dx.doi.org/10.18006/2018.6(2).443.452

\section{KEYWORDS}

Vitamin C

Lactate dehydrogenase

LDH

Squamous cell carcinoma

9: 10 dimethyl 1:2 benzanthracene

DMBA.

\begin{abstract}
Since the discovery of vitamin C many studies have illustrated its characteristic effect as a tumor prevention agent. Conversely: the extracellular presence of lactate dehydrogenase (LDH) is associated with cell necrosis and tissue breakdown and is therefore considered as a tumor marker. In present study effects of vitamin $\mathrm{C}$ on the levels of oral $\mathrm{LDH}$ was estimated during the development of squamous oral carcinoma. Histological findings of study revealed changes in the oral tissue of the animals treated with dimethyl benzanthracene (DMBA) alone or DMBA associated with vitamin $\mathrm{C}$ such as moderate dysplasia associated with basal cell hyperplasia. Notably: differentiated oral squamous cell carcinoma was observed in the rats belonging to group injected with DMBA after 6 weeks. Otherwise: anaplastic oral carcinoma was observed after 5 weeks in group treated with DMBA and vitamin C. High levels of LDH were detected throughout the induction of the squamous cell carcinoma phases in comparison to the anaplastic phase. These findings demonstrate that the injection of DMBA in association with vitamin $\mathrm{C}$ accelerates the induction of anaplastic carcinoma and that these changes are associated with increased LDH levels in the differentiated squamous carcinoma compared with the undifferentiated carcinomas.
\end{abstract}

* Corresponding author

E-mail: SaharelHadad@ hotmail.com (S. EL Hadad)

Peer review under responsibility of Journal of Experimental Biology and Agricultural Sciences.

Production and Hosting by Horizon Publisher India [HPI] (http://www.horizonpublisherindia.in/).

All rights reserved.
All the article published by Journal of Experimental Biology and Agricultural Sciences is licensed under a Creative Commons Attribution-NonCommercial 4.0 International License Based on a work at www.jebas.org.

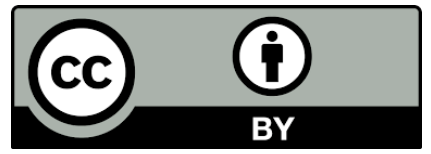




\section{Introduction}

Ascorbic acid (vitamin C) has enormous biological importance and represents one of the most important reducing substances known to occur naturally in living tissues (Iqbal et al, 2004). Although most of animals can synthesize vitamin $\mathrm{C}$ but it cannot be synthesized by humans being and they are totally dependent upon dietary intake to meet their demands. Vitamin $\mathrm{C}$ is known to be essential for enhancing immune response (Holmannová et al., 2012), the structural integrity of the intracellular matrix (Nishikimi et al., 1994), formation of collagens (Jagetia et al., 2007) and hormone synthesis (Kishimoto et al 2013). In addition, numerous studies have reported that vitamin $\mathrm{C}$ can function as a tumor prevention agent and human cancer tissues contain elevated levels of ascorbic acid (Padayatty et al., 2006), and this value was approximately 4-fold higher than those found in tissues of normal origin. The use of vitamin $\mathrm{C}$ in preventing cancer might be ascribable to its requirement in collagen synthesis, which is entire for the protective encapsulation of tumors (May \& Harrison, 2013). Furthermore, vitamin C inhibits lysosomal enzymes, which are responsible for malignant invasion (Cabanillas, 2010).

In contrast, many other studies have rejected the conclusion that vitamin $\mathrm{C}$ prevents or inhibits the development of tumors. High dosages of vitamin $\mathrm{C}$ were shown to induce toxic symptoms in the liver and kidney of rat (Tiwari et al., 1982) and increased the induction of neoplastic and pre-neoplastic lesions of the bladder by nitrosamine. Thus, suggesting its role as a promoter of bladder carcinoma is contradictory (Fukushima et al., 1988). The enhanced role of vitamin $\mathrm{C}$ in this system was thought to result from the large amount of vitamin $\mathrm{C}$ required by the neoplastic cells as compared to normal cells maintain their higher rate of multiplication (Du et al., 2012).

Lactate dehydrogenase (LDH) is an intracellular enzyme that catalyzes the reaction of lactate production via pyruvate reduction during anaerobic glycolysis. Its extracellular presence is associated with cell necrosis and tissue breakdown (Gray et al 2014). Since the discovery of LDH and its importance as a marker of tumorigenesis, it has been utilized as a diagnostic enzyme to distinguish between normal, premalignant, and malignant cells (Andreoli \& Alpern, 1993). Subsequently, a relationship has been established between the concentration of LDH and the development of cancer (Rizwan et al., 2013). Increased LDH activity has been verified in malignant tissues, including in the brain (Palani et al., 2010), lung, stomach, breast and in colon adenocarcinoma and malignant lymphoma (Hu et al., 2015). Furthermore, an increase in the activity of two LDH isoenzymes (LDH 7 and 9) was demonstrated in patients with squamous cell carcinoma (Gorogh et al., 1990).
To further elucidate the mechanisms involved in LDH-mediated cancer progression and the role of vitamin $\mathrm{C}$ therein, a dosedependent study was performed on the promotion of oral squamous cell carcinoma using DMBA in male rats with or without vitamin $\mathrm{C}$ supplementation. LDH activity was also examined as evidence of DNA synthesis and cancer development.

\section{Materials and Methods}

\subsection{Experimental Animals}

Male rats (6-8 weeks old) weighing 150-200g were housed throughout the experimental period in the animal house of the Science Faculty, KAU, Jeddah, KSA. All mice were housed under specific pathogen free conditions including diet at a temperature of $22{ }^{\circ} \mathrm{C}\left(+/-2{ }^{\circ} \mathrm{C}\right)$ with a continuous supply of water. All animal experiments were approved by local authorities in compliance with the Saudi Animal Protection Law.

\subsection{Induction of squamous cell carcinoma in the oral cavities of rats}

9,10 Dimethyl-1,2-benzanthracene (DMBA) (Sigma Aldrich: St. Louis: MO: USA) was used to induce squamous cell carcinoma in the buccal cavities of rats. DMBA was used at $0.5 \%$ dissolved in paraffin oil. For the study of the mechanisms involved in the initiation of oral squamous cell carcinoma and its relation to in situ LDH level,5 percent DMBA were locally injected into the buccal cavity of 20 rats at $0.2 \mathrm{ml} / \mathrm{kg}$ body weight for three times weekly for 4 consecutive weeks (Group III).To limit the consequence of vitamin $\mathrm{C}$ injection on the $\mathrm{LDH}$ level during the initiation of oral carcinoma, 20 rats were injected with $0.2 \mathrm{ml} / \mathrm{kg}$ body weight of $5 \%$ DMBA as for Group III combined with injection of 10 milligram/kilogram body weight vitamin $\mathrm{C}$ through the caudal vein (Group IV). Additionally, two control groups without oral cancer induction (healthy rats) were analyzed, 20 rats served as the untreated control group (Group I) and another 20 rats were injected with $10 \mathrm{mg} /$ kilogram body weight vitamin $\mathrm{C}$ through the caudal vein (Group II).Four rats from each group were euthanized by using ether and the buccal cavity samples were compiled from all the four groups after 1, 3 and 6 weeks from the start of the experiment. The buccal mucosae were removed and stored at $-70{ }^{\circ} \mathrm{C}$ until used.

\subsection{Histological study of the rat oral mucosa}

Small pieces of buccal mucosa cavities were fixed with a $10 \%$ neutral formalin solution for one hour. After fixation, each portion of the specimen was dehydrated in a series of 80, 96 and $100 \%$ ethanol solutions, and then the tissues were cleared in 2 changes of xylene solution and permeated with paraffin. Sections of 5-7 $\mathrm{nm}$ thickness were cut from the longitudinal sections and stained 
with hematoxylin for $2 \mathrm{~min}$ and with eosin for $30 \mathrm{~s}$ (H\&E), dehydrated in an ethyl alcohol concentration series, cleared in xylol and mounted in Canada balsam for light microscopy examination (Rabah et al., 2013).

\subsection{LDH histochemical study}

Pearse's method was employed to demonstrate LDH intensity. Fresh cryostat sections were incubated for $20 \mathrm{~min}$ at $37{ }^{\circ} \mathrm{C}$ in medium containing $20 \mathrm{mg}$ nicotinamide adenine dinucleotide (NAD), $10 \mathrm{mg}$ Nitro blue tetrazolium salt, $1 \mathrm{ml}$ sodium lactate, $2.5 \mathrm{ml} 0.1 \mathrm{M}$ Tris buffer and $1 \mathrm{ml} 0.05 \mathrm{M}$ magnesium chloride with $\mathrm{pH}$ 7.4. Sections were post-fixed at $15 \%$ formal-saline for 15 min, washed in distilled water and mounted in glycerin.

The localization and activity of the LDH enzyme were verified by the presence of blue formazan granules in the cytoplasm whereas the nuclei yielded negative results. The rate of formation precipitation was proportional to the concentration of the enzyme in the rat cheek pouch sections (Pearse, 1980; Pearse, 1985).

\section{Results}

\subsection{Levels of LDH in the control groups (Group I \& II)}

Histological investigation of the untreated rat buccal mucosa sections (Group I) illustrated the presence of flat stratified squamous epithelium without rate pegs, these cells are 4-5 layers in thickness, with occasional keratinization on the surface. The submucosa layer consisted of fibrous connective tissues containing no glands, followed by a layer of longitudinal stratified muscle fibers. Both the epithelium and submucosa layers showed weak LDH activity, whereas the striated muscle layer exhibited moderate LDH activity. On the other hand, sections of rat buccal pouch injected with vitamin C (Group II) appeared to be similar to the untreated group, except that an increase in the keratinized layer was observed after 6 weeks of vitamin $\mathrm{C}$ injection (Figure 1a). This keratinized layer showed a negative reaction for the LDH enzyme, whereas moderate activity was observed in the epithelium and the submucosal connective tissues layers. Intense activity of the LDH enzyme was demonstrated in the striated muscles after 6 weeks of vitamin C injection (Figure 1b).
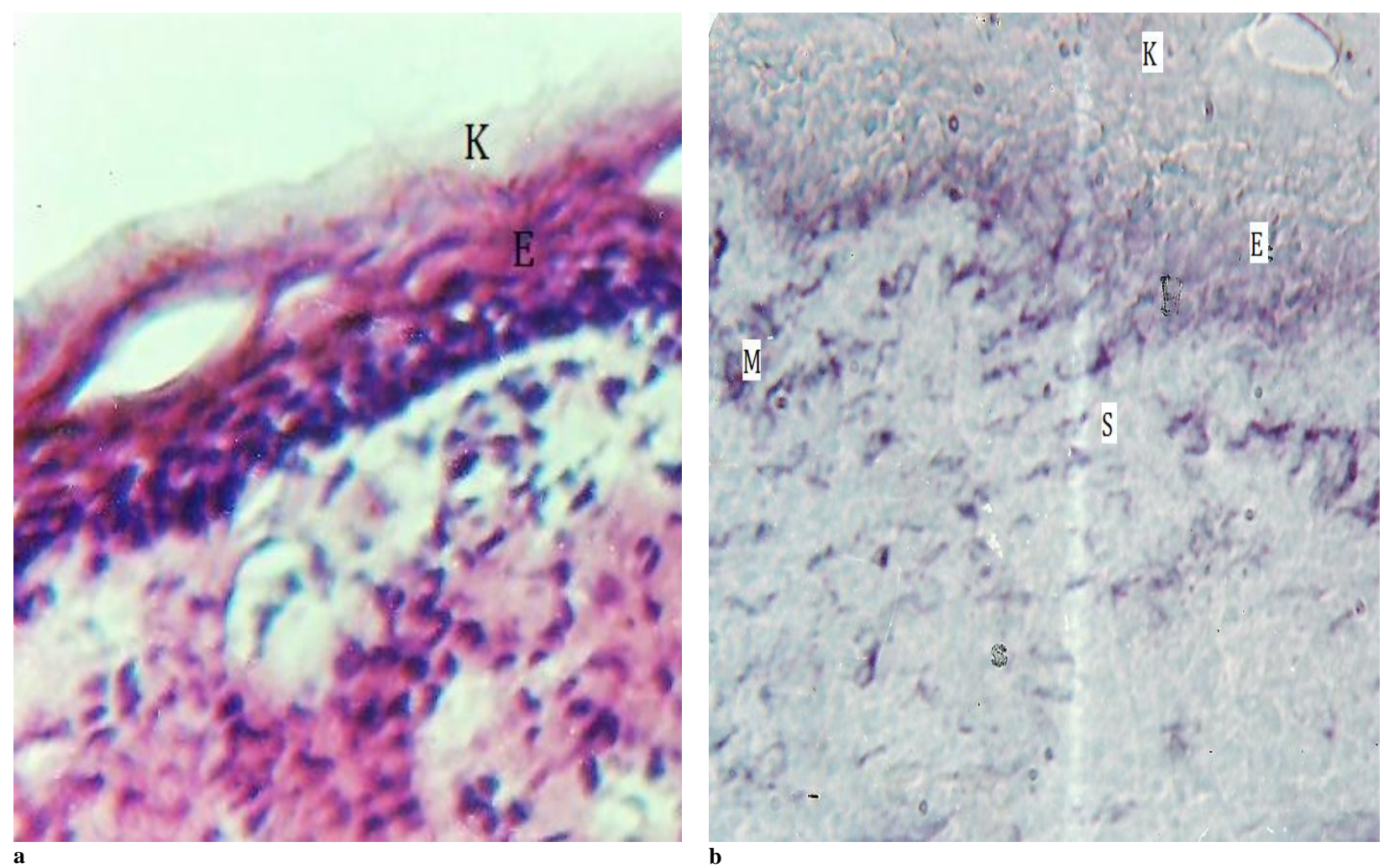

b

Fig. 1. Determination of LDH levels in the rat buccal cavities in the Vitamin $\mathbf{C}$ group. (a) Histological section of rat cheek pouch after 6 weeks of vitamin $\mathrm{C}$ injection characterized by the presence of a keratinized layer (K), whereas the epithelium layer (E) with no rets pegs is still observed. (H\&E) $\times 150$. (b) Rat cheek pouch after 6 weeks' vitamin C injections. Note the moderate LDH activity in the epithelium (E) and the submucosa layers (S); intense activity can be observed at the striated muscle $(\mathrm{M})$, whereas the keratinized layer $(\mathrm{K})$ shows a negative reaction $\times 75$. 


\subsection{Levels of LDH in rats injected with DMBA (Group III)}

After one week of DMBA injections, histological changes in rat buccal cavities indicated the presence of hyperkeratosis and hyperplasia in the form of an increase in the number of epithelial layers associated with some proliferation of the epithelium into the submucosa to form rete pegs. In addition, mild dysplasia in the form of lost polarity and hyperchromassia were observed in some sections (Figure 2a). At this time, a negative reaction was observed for LDH within the keratinized layer, whereas moderate activity was observed in the basal cell layer of the hyperplastic epithelium and submucosal connective tissues whereas intense activity was demonstrated in the striated muscles (Figure 2b).

After 3 weeks of DMBA injection, rat check pouch sections acquired areas of patchy thinning of the epithelium alternating with areas of hyperplasia and papillomatosis. Mild to moderate dysplasia was observed, which was associated with basal cell hyperplasia and moderate hyperkeratosis. An inflammatory cell reaction was observed in the submucosal layer (Figure 3a). The level of the LDH enzyme appeared to be similar overall to that after 1 week of DMBA injection despite the marked to intense LDH activity observed in the epithelium layer around the keratotic crypts and basal cell hyperplasia (Figure 3b).

Severe dysplasia of the epithelium lining and invasive basal cell carcinoma, adenoid cystic type was demonstrated in rat buccal pouch sections exposed to DMBA for 6 weeks. Furthermore, some sections showed an undifferentiated tumor in the form of cords of malignant cells invading into the submucosa with no special arrangement, indicative of developing squamous cell carcinoma (Figure 4a). After 6 weeks of DMBA injections, the adenoid cystic carcinoma showed very intense LDH activity around the nest (Figure 4b).
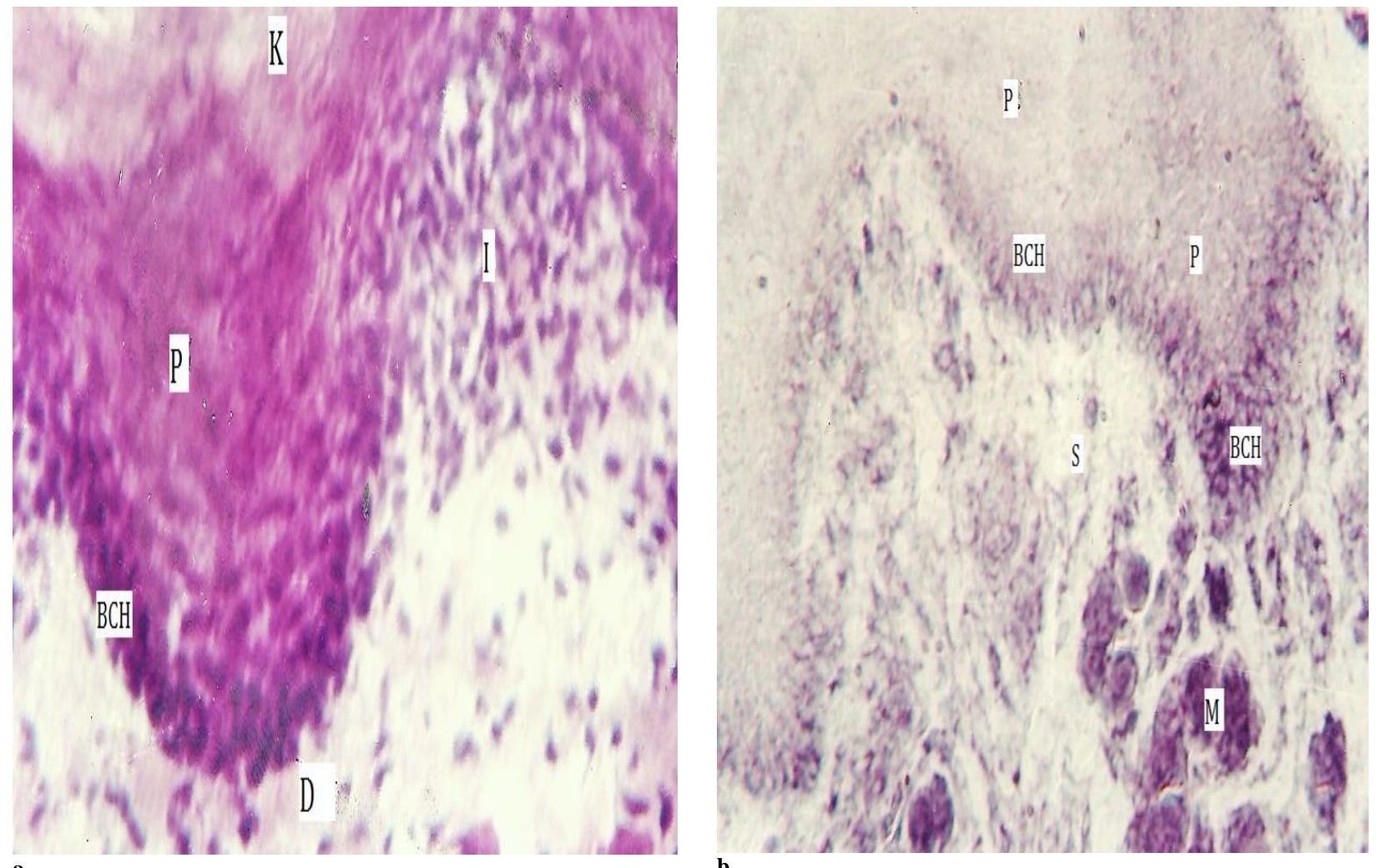

Fig. 2. Determination of LDH in the rat buccal cavities after 1 week of DMBA injections. (a) Histological changes in the rat check pouch indicate the formation of moderate hyperkeratosis $(\mathrm{K})$, papillomatosis $(\mathrm{P})$, and basal cell hyperplasia $(\mathrm{BCH})$. Moderate dysplasia (D) can be detected and an inflammatory reaction (I) is exhibited at the sub-mucosa layer $(\mathrm{H} \& \mathrm{E}) \times 150$. (b) A weak level of LDH can be observed in the epithelium (E) and the submucosa layers (S). Intense activity can be observed at the striated muscle (M), whereas the keratinized layer (K) showed negative reactions. The papillomatosis $(\mathrm{P})$ showed moderate $\mathrm{LDH}$ activity, which is concentrated at the basal cell hyperplasia layers $(\mathrm{BCH})$. The submucosal layer $(\mathrm{S})$ illustrated moderate $\mathrm{LDH}$ activity while the keratinized layer $(\mathrm{K})$ recorded a negative reaction $\times 150$. 

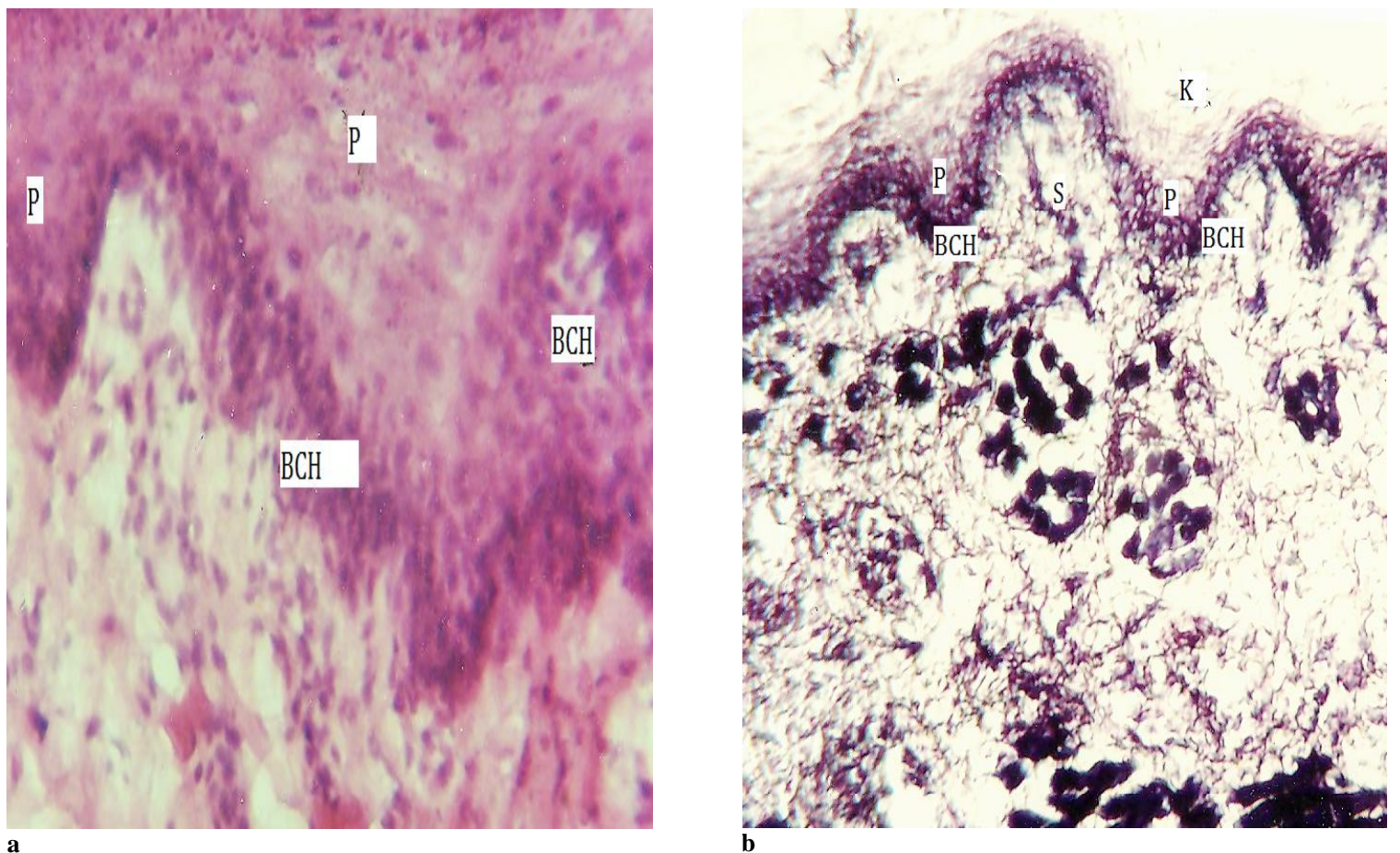

Fig. 3.Determination of LDH in the rat buccal cavities after 3 weeks of DMBA injections. (a) Histological changes in oral pouch sections indicate the presence of papillomatosis $(\mathrm{P})$, and basal cell hyperplasia $(\mathrm{BCH})(\mathrm{H} \& \mathrm{E} \times 150)$. (b) The papillomatosis $(\mathrm{P})$ exhibits increases in LDH activity and intense activity at the basal cell hyperplasia layers $(\mathrm{BCH})$. The submucosal layer (S) shows moderate LDH activity while the keratinized layer (K) exhibits a negative reaction. Intense LDH activity can be observed in the epithelium layer (E) $(\times 75)$.

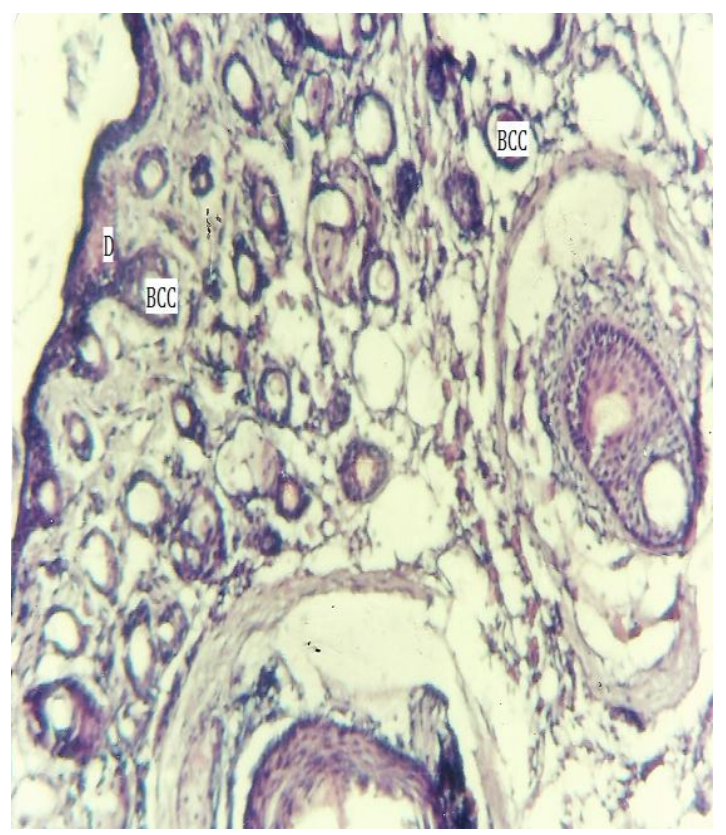

a

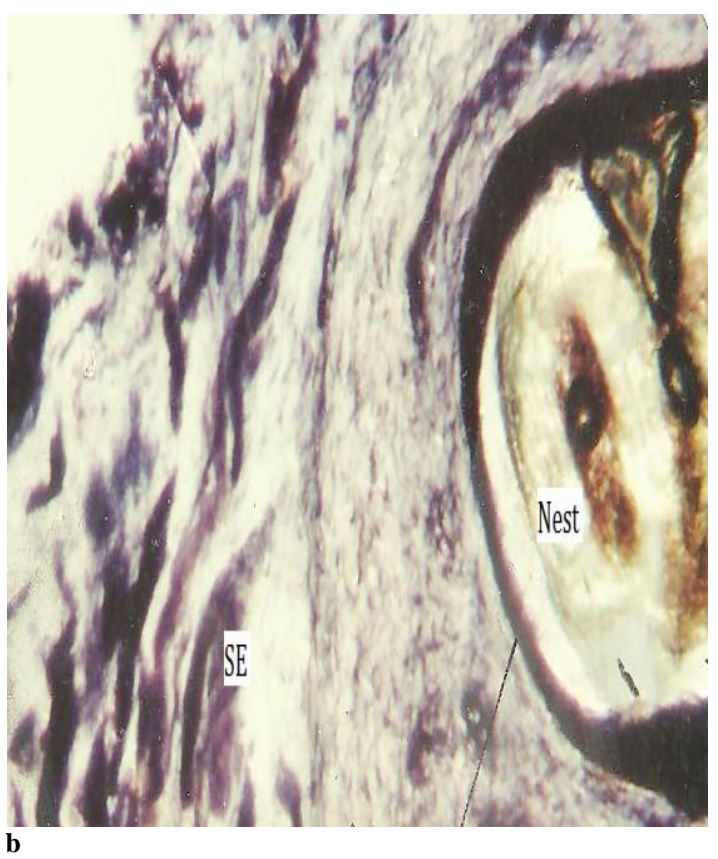

Fig. 4. Determination of LDH in the rat buccal cavities after 6 weeks of DMBA injections. (a) Histological investigation show the formation of basal cell carcinoma (BCC) with adenoid cystic (AC) features, severe dysplasia (D) with basal cell carcinoma (BCC) and the cysts $(\mathrm{CY})$ in the basal cell carcinoma $(\mathrm{H} \& \mathrm{E} \times 150)$. (b) Detection of the very intense LDH activity in the malignant cell sheets (SE) and around the nest of squamous cell carcinoma (Nest) $(\times 75)$.

Journal of Experimental Biology and Agriculture Science http://www.jebas.org 


\subsection{Level of LDH in rats injected with DMBA combined with} vitamin C (Group IV)

Histological investigation of rat buccal sections after one week of DMBA plus vitamin $\mathrm{C}$ injections demonstrated several changes including hyperplasia of the epithelium lining and downward proliferation into the submucosal layer. Moderate dysplasia showed actual papilloma with nuclear changes. The papilloma was associated with buccal cell hyperplasia. In addition, an inflammatory cell reaction was observed in the submucosal layer (Figure 5a). Meanwhile, moderate LDH activity was observed in the basal cells of the hyperplastic epithelium layer and in the striated muscle as well as the submucosa, but a negative LDH reaction of LDH was reported in the keratinized layer (Figure 5b).

The histological criteria of rat check mucosa after 3 weeks of DMBA and vitamin $C$ injections recorded moderate dysplasia and basal cell hyperplasia (Figure 6a). In addition, some histological changes showed keratotic crypts lined by normal epithelium with no signs of malignant development. In current study, the papilloma was characterized by intense LDH activity, observed at the basal layer of the papilloma and around the keratotic crypts (Figure 6b).

In the current study, all the participant animals completed the duration of the experiment except for Group IV. Anaplastic carcinomas were found to have developed in rat buccal pouch sections exposed to DMBA combined with vitamin $\mathrm{C}$ after only 5 weeks, thus demonstrating tumor development at an earlier stage than that observed in Group III, which was injected with DMBA only (Figure 7a). The tumor appeared in the form of scattered undifferentiated malignant cells invading the submucosal layer (Figure 7a). The anaplastic carcinomas investigated after 5 weeks of injections showed a very high increase in the levels of LDH (Figure 7b).

\section{Discussion and Conclusion}

Since the discovery of the carcinogenic effects of tar and its derivatives DMBA, these substances have been used as carcinogens for different organs. This carcinogenicity depends on numbers of known and unknown factors (Starek \& Podolak,
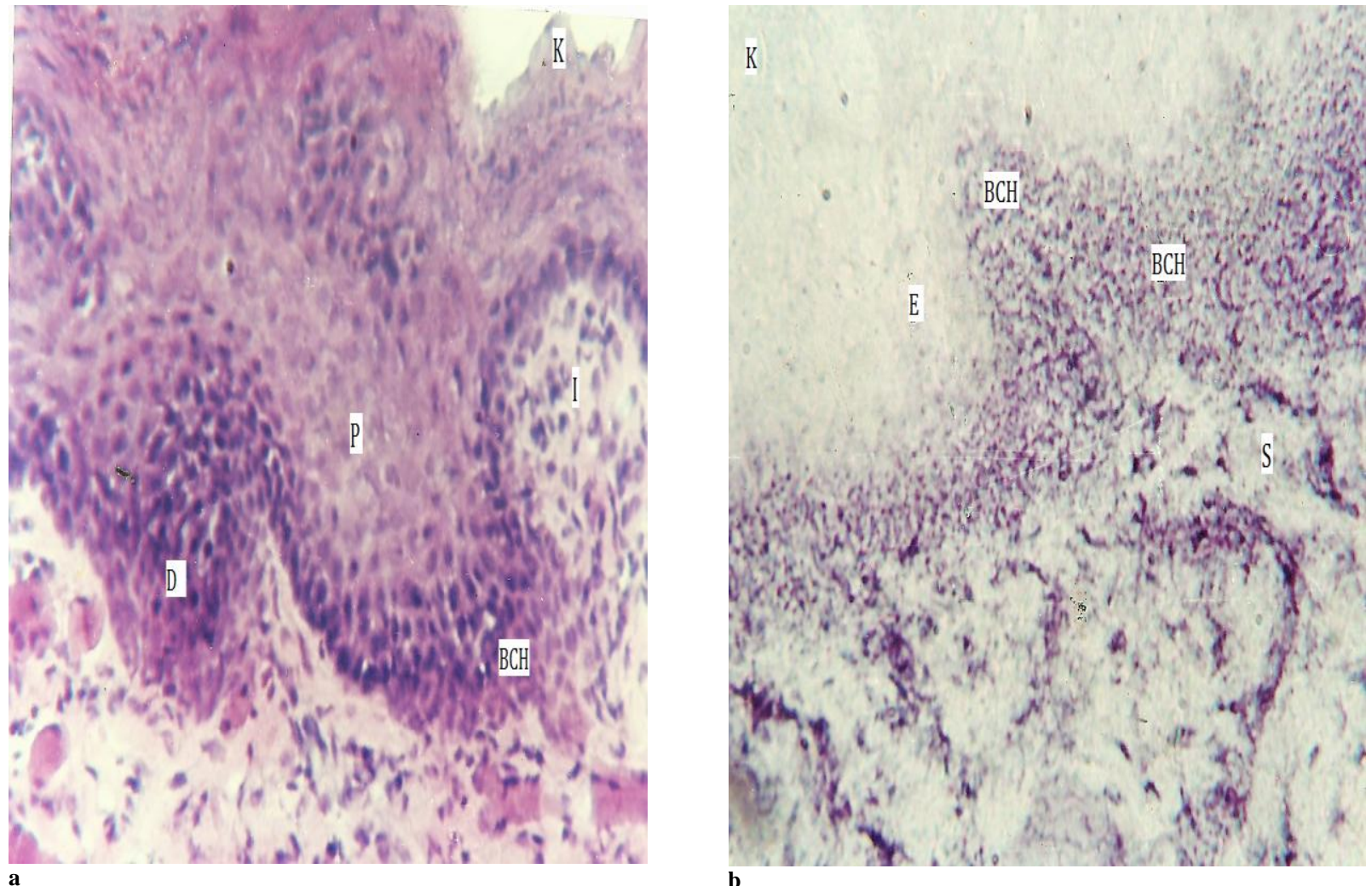

Fig. 5. Determination of LDH in the rat buccal cavities after 1 week of DMBA and vitamin C injection. (a) Histological changes in the rat check pouch indicate the formation of moderate hyperkeratosis $(\mathrm{K})$, moderate dysplasia (D), and basal cell hyperplasia $(\mathrm{BCH})(\mathrm{H} \& \mathrm{E})$ $\times 150$. The epithelium shows actual papilloma (P) and inflammatory cells (I) are observed in the mucosa. (b) A weak level of LDH can be observed in the epithelium (E) and the submucosa layers (S). The keratinized layer shows a negative reaction. Moderate LDH activity is concentrated at the basal cell hyperplasia layers $(\mathrm{BCH})$, whereas a negative reaction is observed in the keratinized layer $(\mathrm{K})(\times 150)$. 

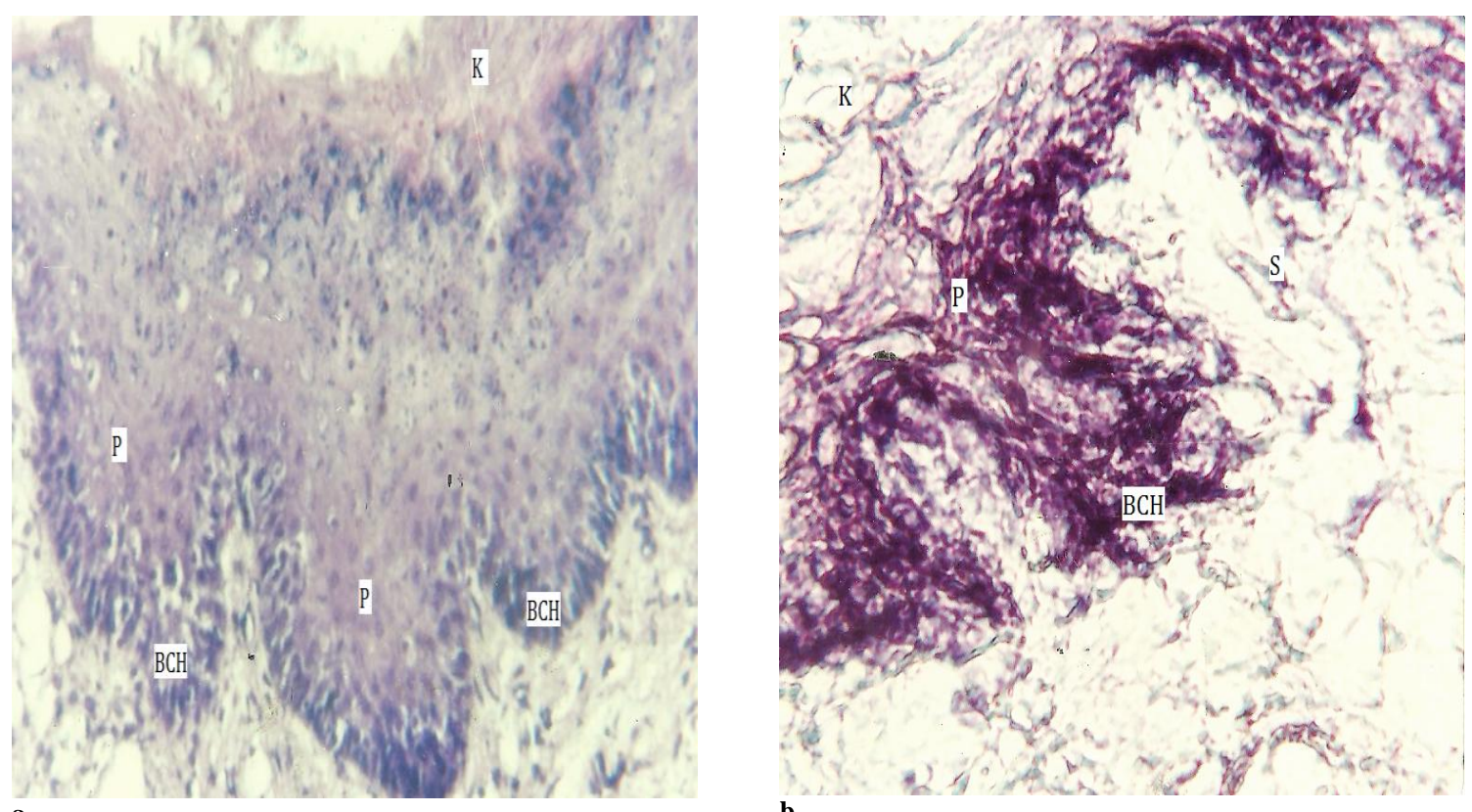

b

Fig. 6. Determination of LDH in the rat buccal cavities after 3 weeks of DMBA and vitamin C injections. (a) Histological changes in oral pouch sections indicate the presence of hyperkeratosis $(\mathrm{K})$, papillomatosis $(\mathrm{P})$, and basal cell hyperplasia $(\mathrm{BCH})$ $(\mathrm{H} \& \mathrm{E} \times 150)$. (b) The papillomatosis $(\mathrm{P})$ shows an increase in LDH activity and intense activity at the basal cell hyperplasia layers $(\mathrm{BCH})$. The submucosal layer $(\mathrm{S})$ shows moderate $\mathrm{LDH}$ activity whereas the keratinized layer $(\mathrm{K})$ shows a negative reaction $(\times 150)$.

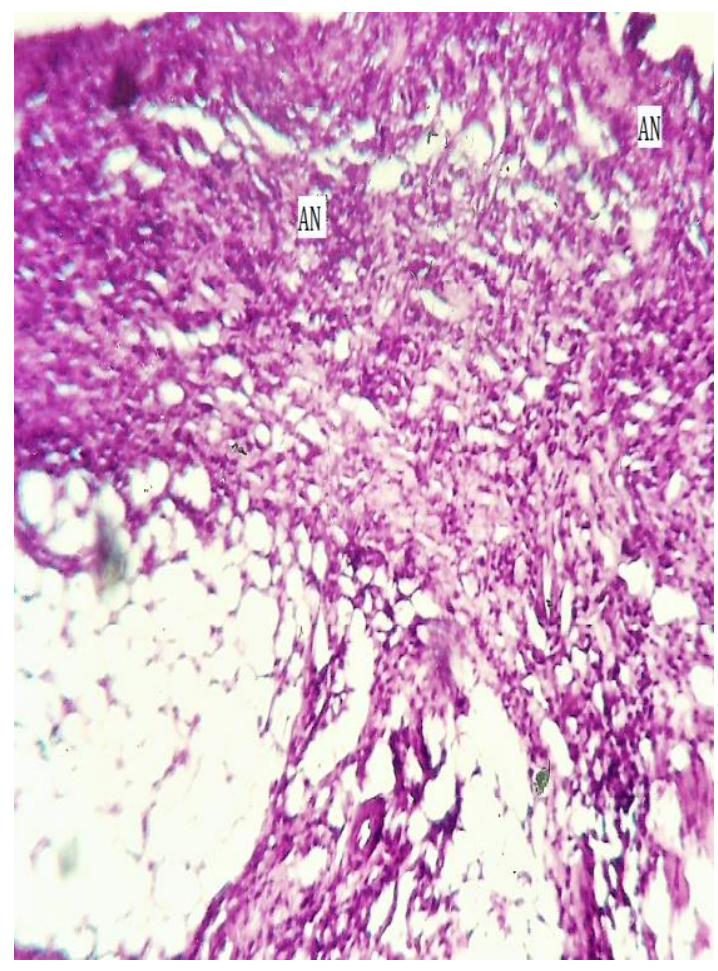

Fig. 7. Determination of $\mathbf{L D H}$ in the rat buccal cavities after 5 weeks of DMBA and vitamin $\mathrm{C}$ injections. Histological changes in oral pouch sections indicate the pretense of anaplastic carcinoma (AN) wherein cellular de-differentiation was detected (H\&E $\times 150)$ (a). Marked LDH activity can be observed in the anaplastic carcinoma (AN) (×75) (b).

Journal of Experimental Biology and Agriculture Science http://www.jebas.org 
2009). The relation between DMBA and the development of check pouch carcinoma was first examining seventy years ago (Levy et al., 1950; Ferguson \& Smillie, 1979; Merch et al., 1979; MacDonald, 1981; Tsiklakis et al.,1987). Present histological investigations demonstrated the initiation of carcinogenesis after the first week of DMBA injections in the form of hyperkeratosis and hyperplasia as well as mild dysplasia, hyperchromassia and some downwards proliferation of the epithelium into the submucosal layer. Areas of patch thinning of the epithelium alternating with areas of hyperplasia, papillomatosis with moderate dysplasia and keratotic crypts lined by benign epithelium with no signs of malignant changes were observed rat buccal pouch sections exposed to DMBA for 3 weeks. The development of squamous cell carcinoma was observed after 6 weeks of DMBA injections. The simultaneous injection of vitamin $\mathrm{C}$ with DMBA yielded no additional histological changes in rats as compared to the rats was injected with DMBA alone after 1 and 3 weeks of injection. After 5 weeks, tumors appeared in the form of scattered malignant cells with no special arrangement. This indicates that vitamin $\mathrm{C}$ injected simultaneously with DMBA accelerated tumor induction such that tumors were founded at an earlier stage than those in the group injected with DMBA alone. This finding was in accordance with the results of previous studies that reported enhancement of the development of laryngeal and tracheal (Harada et al., 1985), bladder (Ito et al., 1984) and forestomach (Imaida et al., 1983) neoplasia in experimental animal groups exposed to different carcinogenic materials combined with vitamin $\mathrm{C}$ which suggested the role of vitamin $\mathrm{C}$ as promoter of various type of carcinoma (Fukushima et al., 1988). In addition, tumor growth was shown to be considerably increased by vitamin $\mathrm{C}$ injected subcutaneously or fed in high concentrations by mouth (Migliozzi, 1977; Maeda et al., 2000).

LDH is a glycolytic enzyme that is widely distributed in all living cells (Schmidt \& Guder., 1979). This enzyme involved in carbohydrate metabolism and is utilized as a marker of glycolysis (Wynder \& Hoffman, 1979). LDH level associated with carbohydrate metabolism was demonstrated in the ovarian tissues also after the injection of medroxyprogestrone acetate (Di Carlo et al., 1984). Role of LDH has been extensively studied in different pathological conditions, especially in cancer. Many studies have reported a weak level of LDH isoenzyme activity in the epithelium layer (Gorogh et al., 1990). Similar findings were observed in the present study in both the epithelium and submucosal layer, whereas moderate LDH activity was observed in the striated muscle layer of rat buccal pouch sections obtained from Groups I and II: which represent control groups. Although some previous studies have maximized the role of vitamin $\mathrm{C}$ as a protective factor against LDH release (Ramos \& Acosta, 1983), others have reported no changes in the LDH levels in mice suffering from vitamin $\mathrm{C}$ deficiency compared to those fed with vitamin C for 21 days (Chen \& Thachker, 1986).

In previous study, LDH concentrations remain constant until malignant lesions were established. These changes were not observed in benign hyperplastic lesions, suggesting that the presence of this enzyme might be worth in the diagnosis of premalignant lesions of hamster oral mucosa (Pereira et al., 2015). Consistent with the previous results, findings of present study revealed that intense level of activity of LDH was detected in the epithelium layer around the keratotic crypts in addition to basal cell hyperplasia after 3 weeks of DMBA injections. Subsequently, very intense LDH activity was observed in adenoid cystic carcinomas within rat buccal pouches injected with DMBA for 6 weeks. This phenomenon has been explained to result from the presence of partial tissue destruction at the neoplastic region (Ninomiya \& Mori, 1985).

The differences in the elevation of LDH activity in different groups in present study attribute the differences of the direct effects of each injected substance. These results might be interpreted as representative of the shift from aerobic toward anaerobic glycolysis. The decrease of LDH activity in anaplastic carcinoma compared to that in differentiated carcinoma (Gill et al., 2016) and has been confirmed by Valvona et al. (2016) who stated that the activity enzymes of the citric acid cycle were inversely proportionate to the mitotic activity. Furthermore, Slavov et al. (2014) studied the relationship between the metabolisms of cell division and tumor growth. They showed that the respiratory production of energy was reduced in mitotic cells where in the energy required for cell division was provided by glycolysis. In addition, Ciesielski-Treska et al. (1972) determined that respiratory metabolism decreased during cell multiplication and increased during differentiation. This might explain the increased enzymatic activity observed in the differentiated compared with the undifferentiated carcinomas. However, Vitamin $\mathrm{C}$ does not increase the LDH levels as a consequence of the development of the undifferentiated cancer cells (Fukushima et al.,1988), in current study reduction in the LDH level was established in the group injected with DMBA combined with vitamin $\mathrm{C}$ for 5 weeks compared to that in the group injected with DMBA alone.

Many previous studies confirmed the increase of serum LDH levels in both oral premalignant and malignant lesions and have shown that serum LDH estimation may serve as a valuable biochemical marker of malignancy (Pereira et al., 2015). In current study injection of vitamin $\mathrm{C}$ in addition to DMBA resulted in an earlier increase the level of LDH in comparison with that obtained in groups $\mathrm{C}$ in addition to DMBA resulted in an earlier increase the level of LDH in comparison with that obtained in 
groups injected with DMBA alone which confirmed the promotional role of vitamin $\mathrm{C}$ on the development of oral squamous cell carcinoma. Otherwise, the level of LDH was decreased in anaplastic (undifferentiated) oral carcinoma (induced by the injection of vitamin $\mathrm{C}$ in addition to DMBA) as compared with that in oral squamous cell (differentiated) carcinomas (resulting from injection of DMBA) which confirmed the decrease the LDH level in the undifferentiated rather than the differentiated oral squamous cell carcinoma. This study suggested that the intravenous vitamin $C$ therapy in cancer treatment should be reassessed according to the types of cancer as well as the stage of the carcinoma.

\section{Abbreviations}

DMBA; 9: 10 dimethyl 1:2 benzanthracene; LDH: lactate dehydrogenase; Vitamin $\mathrm{C}$ : ascorbic acid

\section{Conflict of Interest}

Authors would hereby like to declare that there is no conflict of interests that could possibly arise.

\section{References}

Andreoli TE, Alpern RJ (1993) The physiology of cancer cells. Hospital Practice 28 : 10-17.

Cabanillas F (2010) Vitamin C and cancer: what can we conclude $-1,609$ patients and 33 years later? Puerto Rico Health Sciences Journal $29: 215-217$.

Chen LH, Thachker RR (1986) Vitamin C partially reseved some biochemical changesproduced $b$ Vitamin $E$ deficiency. Biotechnology and Applied Biochemistry 8: 40-45.

Ciesielski-Treska J, Mandel P,Tholey G, Wurtz B (1972) Enzymatic activities modified during multiplication and differentiation of neuroblastoma cells. Nature: New Biology 239:180-181.

Di Carlo F, Racca S, Conti G, Gallo E, Muccioli G, Sapino A, Bussolati G (1984) Effects of long-term administration of high doses of medroxyprogesterone acetate on hormone receptors and target organs in the female rat, Journal of Endocrinology 103: 287-93.

Du J, Cullen JJ, Buettner JR (2012) Ascorbic acid: Chemistry, biology and the treatment of cancer. Biochimica et Biophysica Acta. 1826: 443-457.. doi:10.1016/j.bbcan.2012.06.003.

Ferguson JW, Smillie AC (1979) Vascularization of premalignant lesions in carcinogen-treated hamster cheek pouch. Journal of the National Cancer Institute 63:1383-1392.
Fukushima S, Imaida K, Shibata MA, Tamano S, Kurata Y, Shirai $\mathrm{T}$ (1988) L-ascorbic acid amplification of second-stage bladder carcinogenesis promotion by NaHCO3. Cancer Research 48 :6317-6320.

Gill KS, Tassone P, Hamilton J, Hjelm N, Luginbuhl A, Cognetti D, Tuluc M, Martinez-Outschoorn U, Johnson JM, Curry JM (2016) Thyroid Cancer Metabolism: A Review. Journal of Thyroid Disorders and Therapy 5: 200. doi: 10.4172/21677948.1000200

Gorogh T, Eickbohm JE, Ewers R, Lippert B (1990) Lactate dehydrogenase isoenzymes in squamous cell carcinomas of the oral cavity. Journal of Oral Pathology \& Medicine 9:56-59.

Gray LR, Tompkins SC, Taylor EB (2014) Regulation of pyruvate metabolism and human disease. Cellular and Molecular Life Sciences 71 : 2577-2604. doi: 10.1007/s00018-013-1539-2.

Harada T, Kitazawa T, Maita K, Shirasu Y (1985) Effects of vitamin $\mathrm{C}$ on tumor induction by diethylnitrosamine in the respiratory tract of hamsters exposed to cigarette smoke. Cancer Letters 26:163-169.

Holmannová D, Koláčková M, Krejsek J (2012) Vitamin C and its physiological role with respect to the components of the immune system. Vnitrni Lekarstvi $58: 743-749$.

Hu EC, He JG, Liu ZH, Ni XH, Zheng YG, Gu Q, Zhao ZH, Xiong CM (2015) High levels of serum lactate dehydrogenase correlate with the severity and mortality of idiopathic pulmonary arterial hypertension. Experimental and Therapeutic Medicine 9: 2109-2113.

Imaida K, Fukushima S, Shirai T, Ohtani M, Nakanishi K, Ito N (1983) Promoting activities of butylated hydroxyanisole and butylated hydroxytoluene on 2-stage urinary bladder carcinogenesis and inhibition of gamma-glutamyl transpeptidasepositive foci development in the liver of rats. Carcinogenesis 4:895-899.

Iqbal K, Khan A, Khattak MM (2004) Biological Significance of Ascorbic Acid (Vitamin C) in Human Health. Pakistan Journal of Nutrition 3: 5-13.

Ito N, Fukushima S, Shirai T, Hagiwara A, Imaida K (1984) Drugs food additives and natural products as promoters in rat urinary bladder carcinogenesis. IARC Publications Website 56:399-407.

Jagetia GC, Rajanikant GK, Mallikarjun Rao KVN (2007) Ascorbic acid increases healing of excision wounds of mice whole body exposed to different doses of $\gamma$-radiation. Burns 33:484-494. 
Kishimoto Y, Saito N, Kurita K, Shimokado K, Maruyama N, Ishigami A (2013) Ascorbic acid enhances the expression of type 1 and type 4 collagen and SVCT2 in cultured human skin fibroblasts. Biochemical and Biophysical Research Communications $30: 579-584$.

Levy BM, Gorlin R, Gottsegen RA (1950) Histologic study of the reaction of skin and mucous membrane to a single application of 910 dimethyl-12benzanthracene. Journal of Dental Research 29:678-9.

MacDonald DG (1981) Comparison of epithelial dysplasia in hamster cheek pouch carcinogenesis and human oral mucosa. Journal of Oral Pathology \& Medicine 10:186-191

Maeda N, Hagihara H, Nakata Y, Hiller S, Wilder J, Reddick R (2000) Aortic wall damage in mice unable to synthesize ascorbic acid. Proceedings of the National Academy of Sciences of the United States of America 97:841-846.

May JM, Harrison FE (2013) Role of Vitamin C in the Function of the Vascular Endothelium. Antioxid Redox Signal 19 : 20682083.doi: 10.1089/ars.2013.5205.

Merch LP, Shklar G, Albright J (1979) Transplantation of hamster buccal pouch carcinoma to neonatal hamsters. Oral Surgery, Oral Medicine, Oral Pathology, Oral Radiology 47:533-538.

Migliozzi JA (1977) Effect of ascorbic acid on tumour growth. British Journal of Cancer 35:448-453.

Ninomiya T, Mori M (1985) Histologic and histochemical changes in experimental carcinomas following cryosurgery. International Journal of Oral Surgery 14:362-370.

Nishikimi M, Fukuyama R, Minoshima S, Shimizu N, Yagi K (1994) Cloning and chromosomal mapping of the human nonfunctional gene for l-gulono-gamma-lactone oxidase, the enzyme for 1-ascorbic acid biosynthesis missing in man. Journal of Biological Chemistry 269:13685-13688.

Padayatty SJ, Riordan HD, Hewitt SM, Katz A, Hoffer LJ, Levine M (2006) Intravenously administered vitamin C as cancer therapy: three cases. Canadian Medical Association Journal 174:937-942.

Palani S, Raja S, Sakthivel K, Devi K, Senthil KB (2010) Hepatoprotective and Antioxidant Effects of Monochoria Vaginalis Against Acetaminophen-Induced Hepatotoxicity in Rats. Oriental Pharmacy and Experimental Medicine 10: 29-36.

Pearse AGE (1980) Histochemistry: Theoretical and Applied 4th edition Volume 1 Preparative and Optical Technology pp 1-439 Churchill-Livingstone London.
Pearse AGE (1985) Histochemistry: Theoretical and Applied 4th edition Volume 2 Analytical Technology, Churchill-Livingstone Edinburgh, Pp 441-1055.

Pereira EL, Ramalhosa E, Borges A, Pereira JA, Baptista P (2015) YEAST dynamics during the natural fermentation process of table olives (Negrinha de Freixo cv). Food Microbiology 46:582-586.

Rabah S, El Hadad S, Albani F (2013) Histological changes of Mice lungs after daily exposure to different concentration of Incense smoke. Life Science Journal 10 :552-560.

Ramos K, Acosta D (1983) Prevention by L (-) ascorbic acid of isoproterenol-induced cardiotoxicity in primary cultures of rat myocytes, Toxicology 26:81-90.

Rizwan A, Serganova I, Khanin R, Karabeber H, Ni X, Thakur S, Zakian KL, Blasberg R, Koutcher JA (2013) Relationships between LDH-A lactate and metastases in 4T1 breast tumors. Clinical Cancer Research 19:5158-5169.

Schmidt U, Guder WG (1979) Sites of enzyme activity along the nephron. Kidney 9: 233-242. doi:101038/ki(1976)26.

Slavov N, Budnik BA, Schwab D, Airoldi EM, van Oudenaarden A (2014) Constant growth rate can be supported by decreasing energy flux and increasing aerobic glycolysis. Cell Reports 7:705714.

Starek A, Podolak I (2009) Carcinogenic effect of tobacco smoke. Roczniki Panstwowego ZakladuHigieny 60:299-310.

Tiwari RK, Bandyopadhyay SK, Chatterjee K, Mitra A, Banerjee A, Chatterjee GC (1982) Effects of high dose application of lindane to rats and influence of L-ascorbic acid supplementation. International Journal for Vitamin and Nutrition Research 52: 448455 .

Tsiklakis K, Papadakou A, Angelopoulos AP (1987) The therapeutic effect of an aromatic retinoid (RO-109359) on hamster buccal pouch carcinomas. Oral Surgery, Oral Medicine, Oral Pathology, Oral Radiology 64: 327-332.

Valvona C, Fillmore HL, Nunn PB, Pilkington GJ (2016) The Regulation and Function of Lactate Dehydrogenase A: Therapeutic Potential in Brain. Brain Patholology 26:3-17. doi: 10.1111/bpa.12299.

Wynder EL, Hoffmann D (1979) Tobacco and health: a societal challenge. The New England Journal of Medicine 300: 894-903. 